possibly come from the degradation of the gneiss rocks occurring along the coast. Although corundum is comparatively abundant in the interior of Ceylon, it has never been found in its matrix, but always either in pocket holes in streams, or in drift, intermixed with rounded pebbles of quartz. The character of the rivers in the neighbourhood of the coast apparently precludes the possibility of fragments of corundum being carried down to the sea.

A closer examination of the structure of the beach reveals the fact that the heavier particles are frequently deposited in extremely thin strata, transverse sections of which exhibit the most beautiful curves. Examples of this are seen in Figs. $I$ and 2 , which are half the natural size, the light parts representing quartz, the dark ones

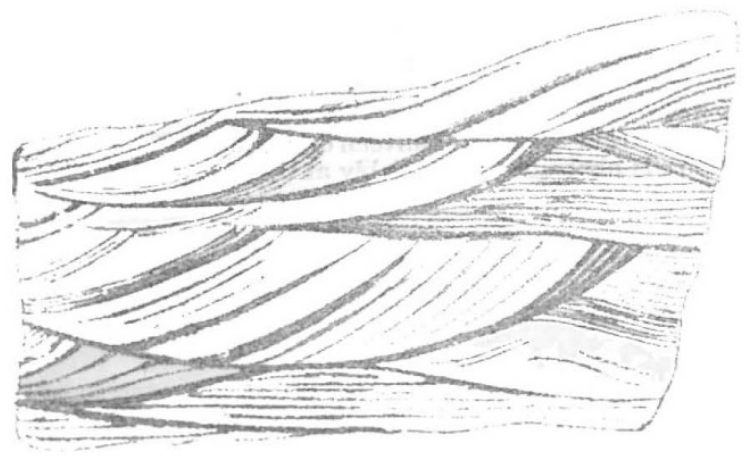

Fig. r.-About one-fourth natural size.

magnetite. The explanation of this is apparently simple. When the quartz fragments of which the larger portion of the rock is formed bave become consolidated, depressions will be formed by the heavy particles of magnetite under the influence of the waves, very much after the manner in which pocket holes are formed in the rocky beds of nearly all the mountain streams in the island. (It was in these pocket-holes that the earlier sapphires were nearly always found.) When once commenced this scouring process would go on as long as the water was sufficiently agitated to keep the fragments of magnetite in motion. Their superior weight would have a tendency to keep them in the hollows they had formed, and the carbonate of lime in the water would fix them in position as soon as they were left undisturbed by the waves. The succeeding waves

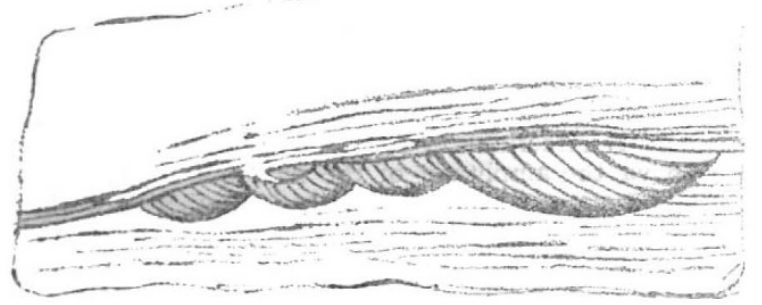

FIG. 2.-About one-fourth natural size.

hat reached the hollow would fill it chiefly with quartz fragments which would become cemented together, and the process of scouring would go on as before.

It may be noticed in explanation of the very beautiful skein-like appearance of Fig. 2, that when once a stratum of magnetite had become consolidated, it would be much less liable to be removed by the scouring process than the neighbouring quartz, on account of its superior hardness, and therefore the original shape of the basin has been retained, whilst other basins, represented by the dark lines, have been formed above it, differing only slightly in shape from the original one. Some portions of this beach are quarried for edging and coping stones which are sent to Colombo. R. ABbAY

\section{ON THE POTENTIAL DIMENSIONS OF} DIFFERENTIATED ENERG $Y^{\mathrm{I}}$

$\mathrm{T}$ his great work, which appears to be but little known $I$ in England, "Ueber die stille Bewegung hypote. tischer Körper," Prof. Hans points out that the dimensions of "ideal" matter may not only differ in degree, but also in kind. He deduces, by means of implicit reasoning from his three primitive "stations," that not only must there be space of $4,5,6, \& c$., dimensions, but also that there must be space of $-\mathrm{I},-3,-5$, \&c., dimensions, and that there may be space of $-2,-4,-6$, $\&$ c., dimensions. Pursuing Hans's train of thought further, Lobwirmski has quite recently interpreted space of $I \cdot I, I \cdot 2$, $r^{*} 3$, \&c., dimensions. Not only has fractional space been thus proved to exist, but the same philosopher has also conclusively shown that if space of $n \cdot \sqrt{-I}$ exists, it has all the properties of angular magnitude; e.g. like all partly bounded infinities (theilweise begränzte Unendlichkeiten), it is unmagnifiable.

These speculations, which are really rather more hyperphysical than metaphysical, immediately suggest the analogous kinematic considerations, and have led me to examine the potential dimensions of differentiated energy. Before pointing out the main conclusion to which I have been led, let me make quite clear the meaning of the terms employed. "Differentiated energy" is that energy which would survive if all matter were destroyed, and simultaneously re-created in such a manner that all its properties were inverted. By "potential dimension" $i$ mean the dimension which, by reason of the kinetic energy of all other dimensions, is only able to vary according to Lobwirmski's groove (Kleise).

Let us start from the idea of what is ordinarily conceived to be a Thing, and imagine the Thing itself (not its measure) to be saturated with the property $a$, after the manner in which the circle is saturated with the straight line in the spiral watch-spring (spiralförmiger Haasesprung einer $W a c h t)$. Further, let us suppose $a$ to change in such a way that all previous values of any one attribute other than those dependent on its rate of variation can be arranged in a series, the functionally alternate terms of which, up to a certain number whose value will be given by taking each turn separately, and finding to what amount its a property may, under the influence of the given "groove" exceed the $a$-property of its immediately antecedent term, represent any convenient converging series. The vigour of this change being, as usual, measured by the degree of matter affected, and also by the index of change in a given time, we have at once the simple relationship

$$
a=\left\{\begin{array}{l}
\beta \\
\gamma
\end{array}\right.
$$

Accordingly, it is obvious as one of the simplest corollaries from the above, that if we know the present position, mass, direction of motion, and velocity of a given piece of matter, we should be able within certain linifts to calculate its chemical composition.

As an example of the application of this let us suppose that the earth's satellite $M$ has the class $C$; let its direction of motion at any given time $\boldsymbol{q}$ be $\mathbf{N}$, Let its rectangular co-ordinates, at the same time, measured from the absolute zero of position, be $m-n$, and $p$. Let $O$ be its velocity, and $H$ an arbitrary constant. We have, substituting in the above equation-

$$
\mathrm{M}=\mathrm{C}_{m} \mathrm{~N}_{n} \mathrm{O}_{p} \mathrm{H}_{q}
$$

which has, at least, no closer resemblance to any other body than it has to caseine.

A. V. NUDELN

I The correspondent who has received the above letter has forwarded it to us for publication. We are not aware that the general scientific opinion in Germany is in consonance with the results reached in the letter. 